\title{
High dielectric constant polyaniline/poly(acrylic acid) composites prepared by in situ polymerization
}

\author{
Chao-Hsien Ho ${ }^{\mathrm{a}}$, Cheng-Dar Liu ${ }^{\mathrm{b}}$, Chia-Hung Hsieh ${ }^{\mathrm{a}}$, Kuo-Huang Hsieh ${ }^{\mathrm{b}}$, Sung-Nung Lee ${ }^{\mathrm{a}, *}$ \\ a Department of Chemistry, Fu-Jen Catholic University, 510 Chung-Cheng Street, Hsin-Chuang, Taipei, Taiwan, ROC \\ ${ }^{\mathrm{b}}$ Institute of Polymer Science E' Engineering, National Taiwan University, Taipei, Taiwan, ROC
}

\section{A R T I C L E I N F O}

\section{Article history:}

Received 6 June 2007

Received in revised form 24 January 2008

Accepted 15 April 2008

Available online 12 June 2008

\section{Keywords:}

Ultra-high dielectric constant

Polyaniline composite

SEM morphology

Nano-scale PANI particle

Mini capacitor

\begin{abstract}
A B S T R A C T
An ultra-high dielectric constant composite of polyaniline, PANI-DBSA/PAA, was synthesized using in situ polymerization of aniline in an aqueous dispersion of poly-acrylic acid (PAA) in the presence of dodecylbenzene sulfonate (DBSA). The water-soluble PAA served as a polymeric stabilizer, protecting the PANI particles from macroscopic aggregation. A very high dielectric constant of ca. $2.0 \times 10^{5}$ (at $\left.1 \mathrm{kHz}\right)$ was obtained for the composite containing 30\% PANI by weight. The influence of the PANI content on the morphological, dielectric and electrical properties of the composites was investigated. The frequency dependence of dielectric permittivity, dielectric loss, loss tangent and electric modulus were analyzed in the frequency range from $0.5 \mathrm{kHz}$ to $10 \mathrm{MHz}$. SEM micrograph revealed that composites with high PANI content (i.e., $20 \mathrm{wt} \%$ ) consisted of numerous nano-scale PANI particles that were evenly distributed within the PAA matrix. The high dielectric constants of these composites were attributed to the sum of the small capacitors of the PANI particles.
\end{abstract}

(c) 2008 Elsevier B.V. All rights reserved.

\section{Introduction}

Polymer composites with high dielectric constants are being developed by the electronics industry in response to the need for power-ground decoupling to secure the integrity of high speed signals and to reduce electromagnetic interference (EMI) [1-4]. On the other hand, fabrication of thin film capacitors on multi-chip modules is essential for downsizing circuits in high speed electronic systems. Thus, developing a substrate-compatible polymer composite of high dielectric constant is a major challenge of integral capacitor technology [5-10]. In addition, electroactive polymers (EAPs), which possess mechanical properties, such as flexibility and light-weight, make it attractive for use in a broad range of electromechanical applications [11-14]. A polymer composite with a large dielectric constant significantly reduces the field required to generate high strain with high elastic energy density [11]. Many new technological applications require energy storage capacitors (i.e., batteries) in order to be functional: pulsed-power applications, power-conditioning applications and solar cell systems [15-18]. High energy density capacitors usually are made of multiple, thin layers of high dielectric constant insulating material.

High dielectric constants have been reported for a variety of materials in recent years, including ceramics, ceramic/polymer

\footnotetext{
* Corresponding author. Tel.: +886 22905 2475; fax: +886 227918687 . E-mail address: 002231@mail.FJU.edu.tw (S.-N. Lee).
}

and polymer/polymer (or organic/polymer) composites. A piezoelectric ceramic material with a very high dielectric constant $\left(\varepsilon_{\mathrm{r}}>6000\right)$ had been used as an ultrasound transducer in medical imaging [16]. In addition, a percolative $\mathrm{BaTiO}_{3}-\mathrm{Ni}$ ceramic composite was reported to have an exceptionally high dielectric constant $\left(\varepsilon_{\mathrm{r}} \sim 8 \times 10^{4}\right)$ [19]. Furthermore, an extra high dielectric permittivity $\left(6.5 \times 10^{4}\right)$ was obtained at room temperature for La-modified $\mathrm{PbTiO}_{3}$ (PLT) with A-site vacancy [20]. On the other hand, ceramic/polymer composites have been of great interest to many researchers for use as embedded-capacitor materials because they combine the processing qualities of polymers with the high dielectric constant of ceramics. Novel nanostructure composites made of epoxy and lead magnesium niobate-lead titanate $(\mathrm{PMN}-\mathrm{PT}) / \mathrm{BaTiO}_{3}$ were reported to have high dielectric constants $\left(\varepsilon_{\mathrm{r}}, 110-1000\right)$ [6,9]. A thin-film $\mathrm{BaTiO}_{3} / \mathrm{PTFE}$ (polytetrafluoroethylene) composite, produced using a pulsed-laser deposition method, reportedly exhibited a very high dielectric permittivity $\left(\varepsilon_{\mathrm{r}}=4000-10,000\right)$ when tested at a frequency of $10 \mathrm{kHz}$ [14].

Polyaniline (PANI) has emerged as one of the most promising conducting organic polymers, owing to its high polymerization yield, good environmental stability, moderate electrical conductivity and relatively low production cost. There are several reports of high dielectric constant composites of PANI and some PANI/polymer blends. For instance, a dielectric constant of $10^{4}$ was observed in a partially crystallized PANI material [21]. High dielectric constant values ranging between ca. 200 and 1000 have been 
reported for PANI/PVA (poly vinyl alcohol) composites [22]. In addition, a hyper-branched PANI material polymerized using sonication had a high dielectric constant $>10^{4}$ [23]. Recently, PANI/epoxy composites prepared via an in situ polymerization process were reported to have dielectric constants approaching 3000 at $10 \mathrm{kHz}$ [24]. On the other hand, the synthesis of colloidal PANI particles and their application in PANI/polymer composites is of great interest as an attractive alternative for overcoming the poor processability of PANI. While PANI is insoluble in common organic solvents and lacks infusibility [25,26], colloidal PANI particles can be completely dispersed in a polymer medium due to their size. Usually, PANI particles are produced with a suitable polymeric stabilizer, such as poly(vinyl alcohol) [27,28], or cellulose ether [29], etc., which prevents macroscopic aggregation.

A novel high dielectric constant polyaniline-dodecylbenzenesulfonic acid/polyurethane (PANI-DBSA/PU) blend $\left(\varepsilon_{\mathrm{r}} \sim 1120\right)$ was previously developed in our laboratory via in situ polymerization technique [30]. In the present study, the same polymerization technique was employed to synthesize a dispersion of PANI particles, and poly(acrylic acid) (PAA) was used to form the matrix and to stabilize the dispersion. We expect the PANI particles would be well dispersed within the PAA polymer matrix due to the strong interaction between PANI and PAA. Similar strong interaction has been observed in various PANI-PAA blends $[31,32]$ as well as selfassembled PANI-PAA films [33]. The effect of PANI content on dielectric and electrical properties of PANI-DBSA/PAA composites was investigated. Frequency-dependency of various dielectric behaviors for these composites also was studied in the range of $0.1 \mathrm{kHz}$ to $10 \mathrm{MHz}$. Relationships between composite microstructures and dielectric properties were examined.

\section{Experimental}

\subsection{Materials}

Aniline and acrylic acid were purchased from Aldrich Co. Dodecylbenzene sulfonic acid (DBSA), and ammonium peroxydisulfate (APS) were obtained from Junsei Chemical Co., Japan. All reagents were used as received without further purification. De-ionized water was used in preparation of all aqueous solutions.

\subsection{Preparation of $P A A$}

Five grams of acrylic acid were dissolved in $60 \mathrm{ml}$ of water and stirred in a water bath at $70^{\circ} \mathrm{C}$. To initiate polymerization, an initiator solution of APS was prepared $(0.04 \mathrm{~g}$ in $1 \mathrm{ml}$ of water) and added drop-wise to the acrylic acid solution. The molar ratio of acrylic acid to APS was 80 to 1 . The polymerization reaction was continued for a period of $1.5 \mathrm{~h}$. The Mw of PAA obtained was 80,100 and PDI is 1.63 , as determined by gel permeation chromatography (GPC, Fig. 1).

\subsection{Preparation of PANI-DBSA/PAA composites}

The compositions of these composites are listed in Table 1, and were prepared as follows: aniline and DBSA were added, with stirring (ca. $150 \mathrm{rpm}$ ), to the freshly synthesized PAA solution after it had cooled to room temperature $\left(25^{\circ} \mathrm{C}\right)$. The resulting mixture was then cooled to $0-5^{\circ} \mathrm{C}$ and stirred for $1 \mathrm{~h}$. Next, a solution of APS (dissolved in $5 \mathrm{ml}$ of ice-cold water) was slowly added to the reaction mixture. The mixture was stirred for $8 \mathrm{~h}$ at $0-5{ }^{\circ} \mathrm{C}$ to complete the polymerization of aniline. The color of the mixture changed from white to blue to dark green. A stable, PANI-DBSA/PAA dispersion was obtained after polymerization.

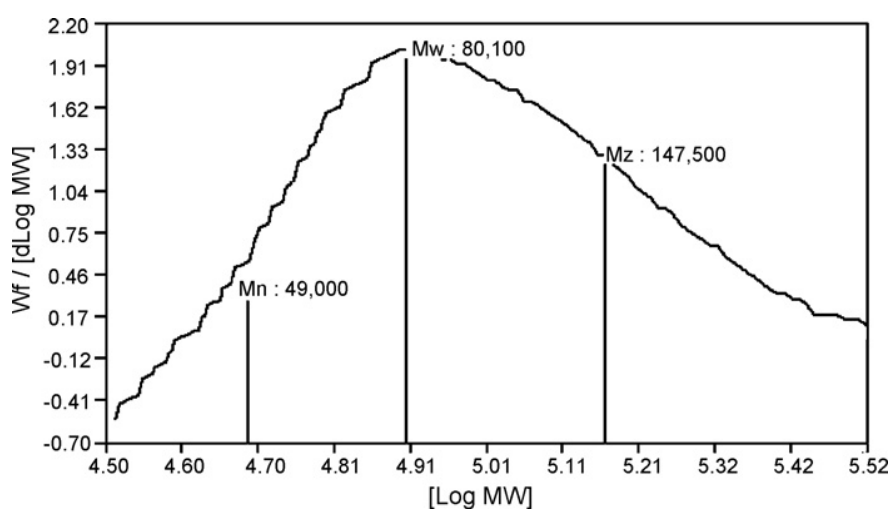

Fig. 1. Gel permeation chromatography of poly(acrylic acid).

Pure PANI-DBSA complex was synthesized using previously reported methods [30].

\subsection{Characterization}

A Waters $501 \mathrm{HPLC}$ pump system with a $300 \mathrm{~mm} \times 7.5 \mathrm{~mm}$ PLgel column $(5 \mu \mathrm{m})$ was used for GPC analysis with tetrahydrofuran $\left(1 \mathrm{ml} \mathrm{min}^{-1}\right)$ as the eluent. The eluent was monitored with a laser refractometer (Viscotek model LR 40). The column was calibrated by using narrow and broad polystyrene standards which were purchased from American Polymer Standards Corp. Test specimens were prepared by spin-coating a preheated glass plate $\left(\sim 100^{\circ} \mathrm{C}\right)$ with the PANI-DBSA/PAA dispersion one layer at a time. Samples with a thickness of ca. $0.5 \mathrm{~mm}$ were obtained by applying approximately 15 layers. The specimen was dried in an oven at $80^{\circ} \mathrm{C}$ for $24 \mathrm{~h}$. SEM was performed using an JEOL JSM-6500F field emission scanning electron microscope operated at $1.0 \mathrm{kV}$ and $10 \mathrm{kV}$. The sample was frozen in liquid nitrogen and the resulting freshly fractured surface was examined. Dielectric spectroscopy was performed using an HP4192LF model impedance analyzer system. Circular samples, approximately $1.5 \mathrm{~cm}$ in diameter with a thickness of ca. $0.5 \mathrm{~mm}$, onto which silver electrodes had been painted, were tested.

Measurements of capacitance ( $C$, in Farad) and conductance ( $G$, in Siemen) were made over the range of $0.5 \mathrm{kHz}$ to $2 \mathrm{MHz}$. The dielectric constant $\left(\varepsilon_{\mathrm{r}}\right)$ and dielectric loss $\left(\varepsilon^{\prime \prime}\right)$ values were calculated from capacitance and conductance using the following equations:

$\varepsilon_{\mathrm{r}}=\frac{4 C t}{\pi d^{2}}$

$\varepsilon^{\prime \prime}=\frac{G}{2 \pi f \mathrm{Co}_{0}}$

where $t$ is the thickness and $d$ is the diameter of the sample, $f$ is the frequency of the applied AC-field and Co is the capacitance of the parallel electrodes without the sample. In addition, the electrical conductivity $(\sigma)$ was measured using the standard four-probe method.

\section{Results and discussion}

Fig. 2 depicts the morphologies of the pure PAA sample at magnifications of $10 \mathrm{~K}$ and $50 \mathrm{~K}$, respectively. The micrograph of PAA reveals a smooth, continuous phase at $10 \mathrm{~K}$ (Fig. 2a). As the magnification was increased to $50 \mathrm{~K}$, the high thermal energy required for SEM detection burned the PAA film; thus, cracked structures appeared. The SEM micrograph of pure PANI-DBSA on carbon tape is shown in Fig. 3. This pure PANI-DBSA complex was synthe- 
Table 1

The compositions and characteristics of PANI-DBSA/PAA composites ${ }^{+}$

\begin{tabular}{|c|c|c|c|c|c|c|c|c|}
\hline \multirow[t]{2}{*}{ PANI } & \multicolumn{4}{|c|}{ Compositions (g) } & \multirow[t]{2}{*}{ Particle size $^{\mathrm{a}}(\mathrm{nm})$} & \multirow[t]{2}{*}{ Separation between particles ${ }^{\mathrm{a}}(\mathrm{nm})$} & \multirow[t]{2}{*}{$\varepsilon_{\mathrm{r}}, 10^{5}(1 \mathrm{kHz})$} & \multirow[t]{2}{*}{$\sigma, 10^{-4} \mathrm{~S} / \mathrm{cm}$} \\
\hline & Acrylic add & Aniline & DBSA & APS & & & & \\
\hline 7 & 5.0 & 0.35 & 1.23 & 0.86 & 200-2000 (aggregates) & 2000-20,000 (aggregates) & 0.0011 & 0.25 \\
\hline 14 & 5.0 & 0.70 & 2.45 & 1.72 & $50-80$ & $30-1000$ & 0.0026 & 0.32 \\
\hline 20 & 5.0 & 1.00 & 3.51 & 2.45 & $20-50$ & $20-50$ & 0.9 & 2.0 \\
\hline 25 & 5.0 & 1.25 & 4.38 & 3.07 & $20->50$ & $20-50$ & 1.1 & 4.2 \\
\hline 30 & 5.0 & 1.50 & 5.26 & 3.72 & $20->100$ & $20-50$ & 2.0 & 8.3 \\
\hline
\end{tabular}

+ molar ratio of aniline/DBSA/APS $=1 / 1 / 1$.

a By estimation.

(a)

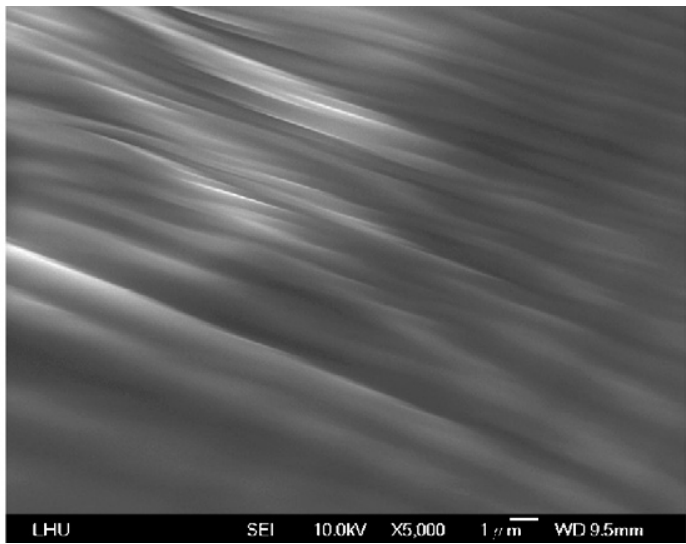

(b)

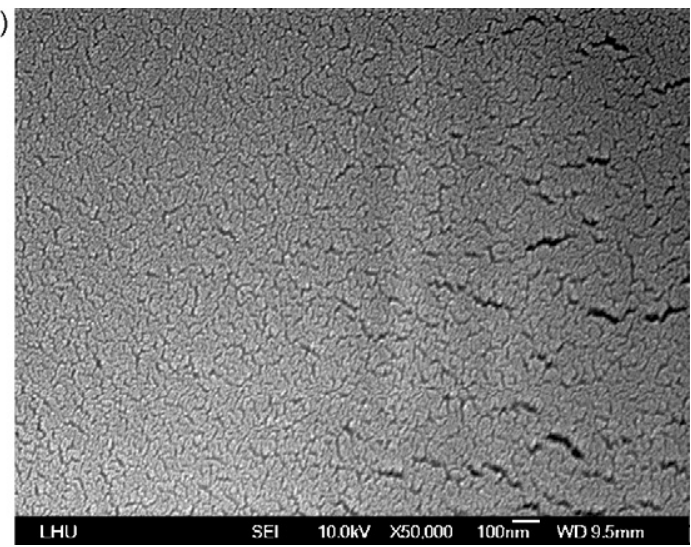

Fig. 2. SEM micrographs of poly(acrylic acid) (PAA) at a magnification of (a) $10 \mathrm{k}$, and (b) $50 \mathrm{k}$.

(a)

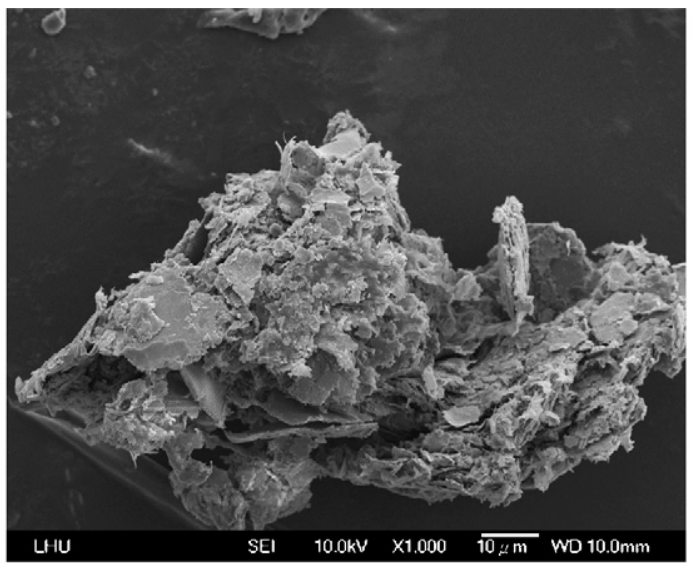

(b)

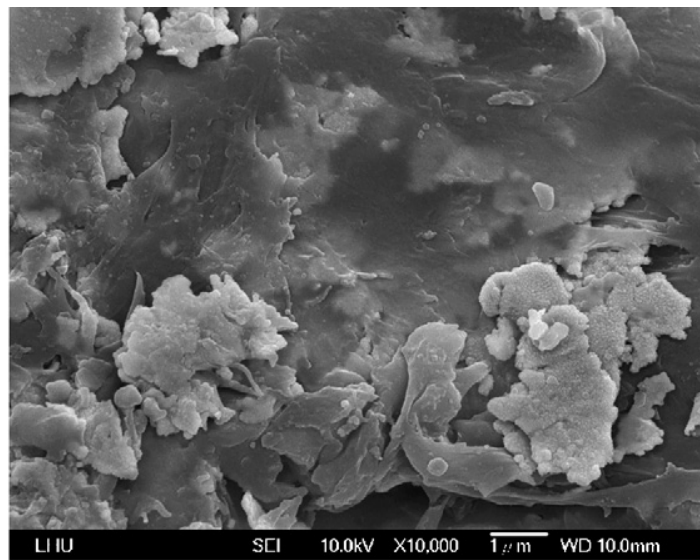

(c)

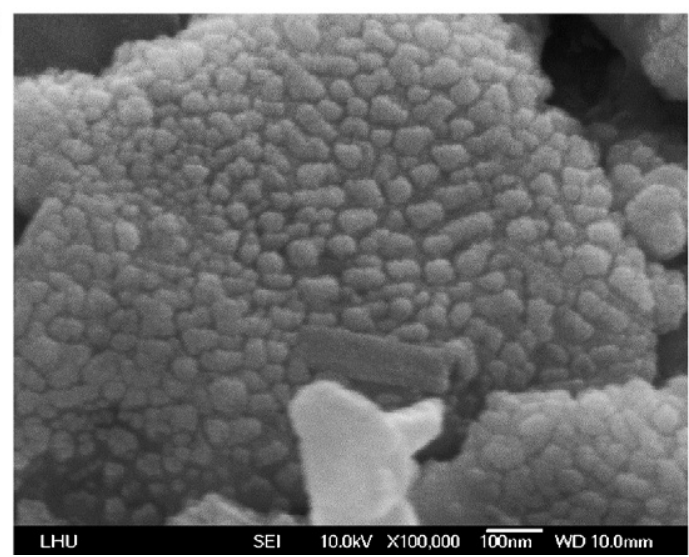

Fig. 3. SEM micrographs of pure PANI-DBSA particles at a magnification of (a) $1 \mathrm{k}$, (b) $10 \mathrm{k}$, and (c) $100 \mathrm{k}$. 
(a)

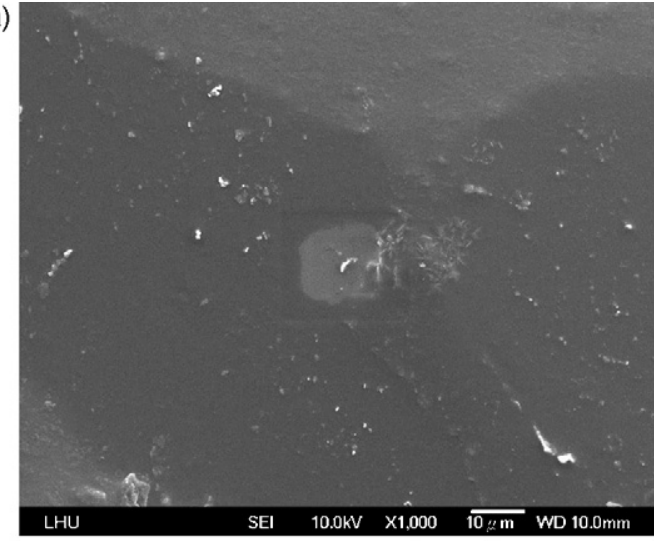

(c)

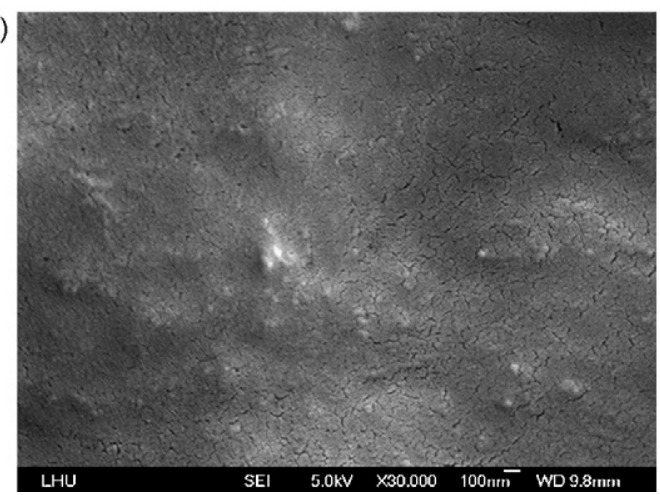

(b)

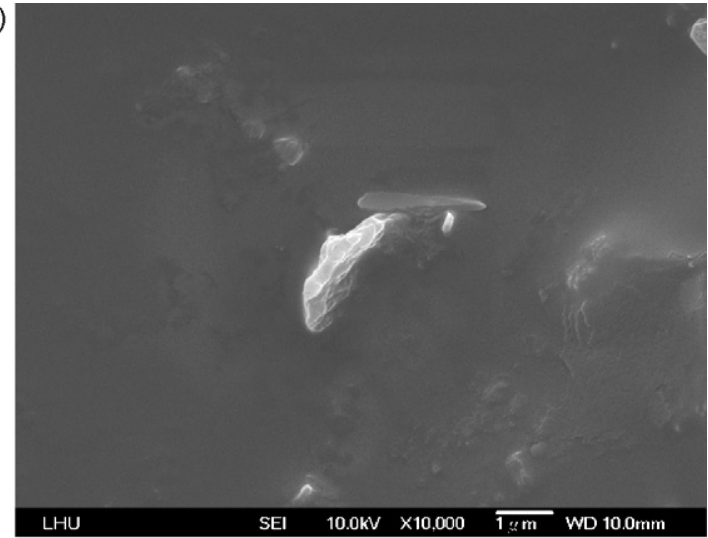

(d)

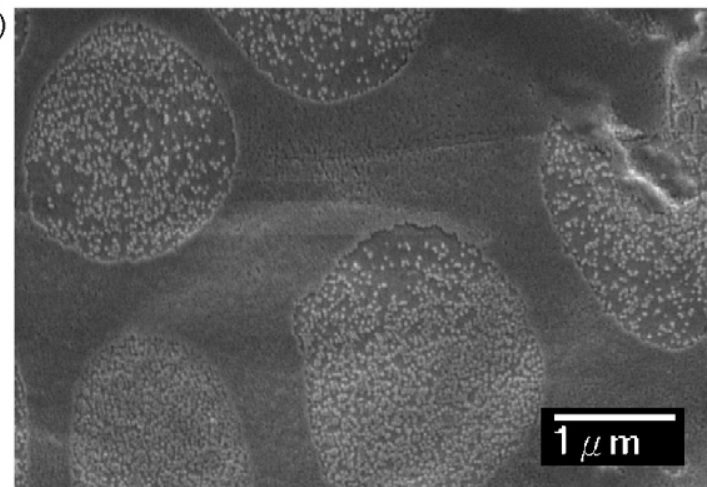

Fig. 4. SEM micrographs of PANI-DBSA/PAA composites containing low PANI contents: (a) $7 \mathrm{wt} \%(\times 1 \mathrm{k})$, (b) $7 \mathrm{wt} \%(\times 10 \mathrm{k})$, (c) $14 \mathrm{wt} \%(\times 30 \mathrm{k})$ and (d) $20 \mathrm{wt} \%(\times 10 \mathrm{k})$.

sized according to the methods reported previously [30], without addition of a polymer stabilizer (e.g., PAA). PANI primary particles ranged in diameter from ca. $30 \mathrm{~nm}$ to $50 \mathrm{~nm}$ (Fig. 3c), first forming aggregates (ca. $0.5-2.0 \mu \mathrm{m}$ in diameter, Fig. $3 \mathrm{~b}$ ), then clustering into agglomerates (Fig. 3a). A similar study performed by other research groups gave comparable results: the average size of the resulting primary particles was ca. $18.7 \mathrm{~nm}$, and its aggregates were $5 \mu \mathrm{m}$ in diameter [34].

Fig. 4a-d, shows SEM micrographs of PANI-DBSA/PAA composites containing $7 \mathrm{wt} \%, 15 \mathrm{wt} \%$ and $20 \mathrm{wt} \%$ PANI-DBSA, respectively. The micrograph of the composite containing $7 \mathrm{wt} \%$ PANI shows the PANI aggregates ranged in size from $0.2 \mu \mathrm{m}$ to $2.0 \mu \mathrm{m}$ and were randomly distributed (Fig. 4a and b) with the distance between these aggregates in the range of ca. $2.0-20 \mu \mathrm{m}$. This barely identifies the PANI primary particles. As the PANI content increased to $15 \mathrm{wt} \%$, the PANI particles of ca. $50-80 \mathrm{~nm}$ in size dispersed among the matrix and the distance between them was approximately $50 \mathrm{~nm}-1.0 \mu \mathrm{m}$ (Fig. 4c). On the other hand, the composite containing $20 \mathrm{wt} \%$ PANI exhibited a morphology very different from that of the $7 \mathrm{wt} \%$ and $15 \mathrm{wt} \%$ PANI composites. Many spherical aggregates with an average diameter of ca. $2.0 \mu \mathrm{m}$ were generated in the matrix, and there were hundreds of tiny PANI particles (in the range of $20-40 \mathrm{~nm}$,) packed within each aggregate. The distance between the aggregates was in the range of $0.2-1.0 \mu \mathrm{m}$, and the distance between PANI particles within an aggregate was approximately $20-30 \mathrm{~nm}$ (Fig. 4d).

Fig. 5a-d depicts the SEM micrographs of the composites containing $25 \mathrm{wt} \%$ and $30 \mathrm{wt} \% \mathrm{PANI}$, respectively. The micrographs showed a similar pattern as compared with that of the $20 \mathrm{wt} \%$ composite. The PANI particles averaged ca. $20-50 \mathrm{~nm}$ in diameter and were evenly distributed throughout the entire PAA matrix. This distance between particles was ca. 20-50 nm (Fig. 5b and c). Aggregation of the nano-scale particles was observed for both the $25 \mathrm{wt} \%$ and $30 \mathrm{wt} \%$ composites, as shown by the bright white spots and bumps (Fig. 5a), as well as by the large grains (ca. $>100 \mathrm{~nm}$, Fig. $5 \mathrm{~d}$ ). Table 1 lists the morphology analysis of various PANI-DBSA/PAA composites studied by SEM along with other physical properties.

The above results can be rationalized that the spherical aggregates are generated from the micelles of DBSA-aniline pair [35] (DBSA/aniline molar ratio: 1/1) when the critical micelle concentration $(\mathrm{CMC})$ is reached. Polymerization mixture with $20 \mathrm{wt} \%$ of PANI seems to be the threshold concentration for the formation of this micellar structure, which helps disperse the anilinium ions and with synthesis of the PANI particles. If the concentration of the DBSA-anilinium pair exceeds the CMC, the micelles (i.e., the spherical aggregates) will burst and the PANI particles will fill the whole matrix quite evenly at the final stage of the reaction. This is exactly what was observed in the SEM micrographs of the composites of $25 \mathrm{wt} \%$ or $30 \mathrm{wt} \%$ of PANI, except that more PANI particles were presented and the sizes of some particles were a little bigger (as shown in Figs. 4d, 5b and c). On the other hand, the PANI particles formed under low aniline-DBSA concentration (as that of the composites containing $7 \mathrm{wt} \%$ of PANI) would coagulate together and formed PANI aggregates of different sizes (ca. 0.2-2.0 $\mu \mathrm{m}$ ) scattering among the matrix (as shown in Fig. 4a and b). Haba et al. [34] have observed that in the beginning of the polymerization of the aniline-DBSA complex, the SEM shows agglomerates consisting of spherical PANI particles. As polymerization proceeds, the voids among these particles are filled, forming a smooth surface of the PANI agglomerates (particle size ca. 50-100 nm).

When connected to a sinusoidal voltage, $\mathrm{Vc}=V \exp (\mathrm{j} \omega t)$, the total current transversing the parallel plates of a capacitor is given by the following equation $[36,37]$ :

$I_{\mathrm{c}}=I_{\mathrm{ch}}+I_{\mathrm{l}}=(\mathrm{j} \omega C+G) \mathrm{Vc}$ 
(a)

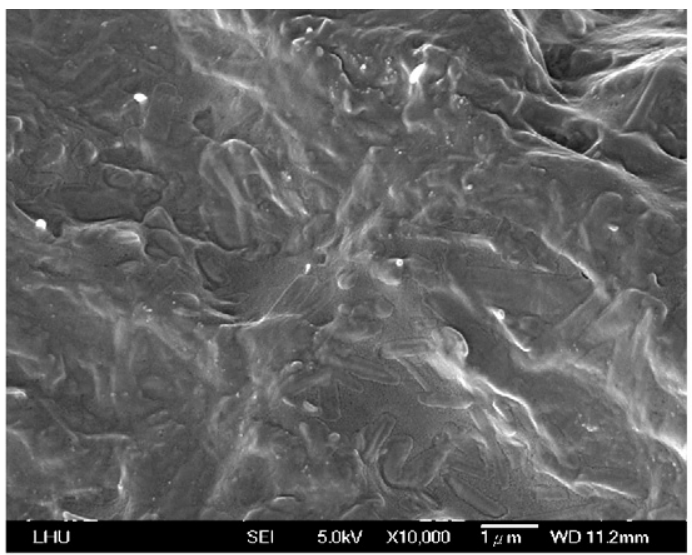

(c)

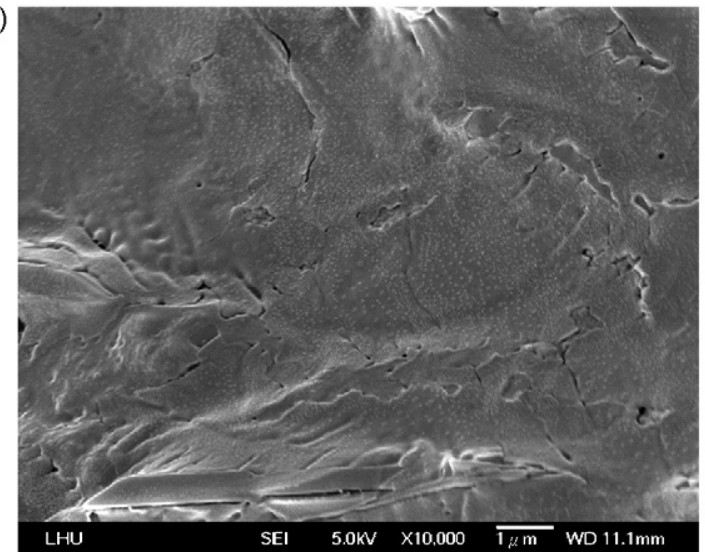

(b)

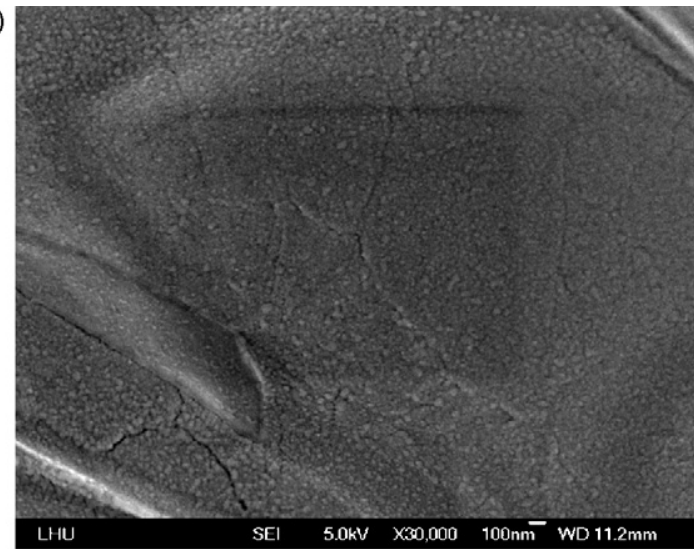

(d)

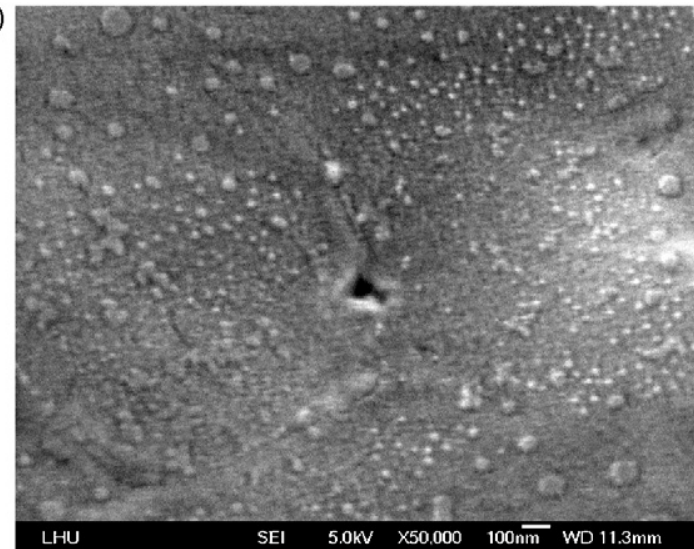

Fig. 5. SEM micrographs of PANI-DBSA/PAA composites containing high PANI contents: (a) $25 \mathrm{wt} \%(\times 10 \mathrm{k}),(\mathrm{b}) 25 \mathrm{wt} \%(\times 30 \mathrm{k}),(\mathrm{c}) 30 \mathrm{wt} \%(\times 10 \mathrm{k})$, and (d) $30 \mathrm{wt} \%(\times 50 \mathrm{k})$.

where $I_{\mathrm{ch}}$ and $I_{1}$ are the charging and loss currents, respectively; $C$ and $G$ are the capacitance and conductance of the dielectric material, respectively; $\omega$ is the AC field applied. Both $C$ and $G$ can be measured from the impedance analyzer as described in Section 2.2.

Both current can be correlated to the complex permittivity $\left(\varepsilon^{*}\right)$ of a dielectric material:

$\varepsilon *=\varepsilon^{\prime}-\mathrm{j} \varepsilon^{\prime \prime}$

where $\varepsilon^{\prime}$ is the real permittivity and $\varepsilon^{\prime \prime}$ is the loss index. The relative permittivity (i.e., dielectric constant), $\varepsilon_{\mathrm{r}}$, is equal to $\varepsilon^{\prime} \mid \varepsilon_{0}$, where $\varepsilon_{0}$ is the permittivity of vacuum. The total current $I_{\mathrm{c}}$ may thus, be rewritten as

$I_{\mathrm{C}}=\left(\mathrm{j} \omega \varepsilon^{\prime}+\omega \varepsilon^{\prime \prime}\right) \operatorname{CoVc}$

Comparing Eqs. (5) and (3), $\mathrm{j} \omega \mathrm{C}=\mathrm{j} \omega \varepsilon^{\prime}$ Co represents the storage, and $G=\omega \varepsilon^{\prime \prime}$ Co represents loss (Co is the capacitance of the capacitor without dielectric material).

And the dissipation factor is defined as ratio of loss to storage:

$\tan \delta=\frac{\varepsilon^{\prime \prime}}{\varepsilon^{\prime}}$

Fig. 6 presents the variation in conductivity with PANI content for the PANI-DBSA/PAA composites. The conductivity increased with additional PANI and a percolation threshold of conductivity $\left(\times 10^{-3} \mathrm{~S} / \mathrm{cm}\right)$ appeared as the PANI content reached $20 \mathrm{wt} \%$ and leveled off (ca. $8.0-9.0 \times 10^{-3} \mathrm{~S} / \mathrm{cm}$ ) at ca. $30 \mathrm{wt} \%$ of PANI was added (Table 1 ). All these results can be explained based on the morphologies of these composites as revealed by the SEM study mentioned above (Figs. 4 and 5). The inter-particle distance decreased as more PANI incorporated, both factors can increase the conductivity of the composites.
Figs. 7-9 depict the dependence of various dielectric behaviors on PANI content and on the frequency of the applied AC field. As shown in Fig. 7, the $\varepsilon_{\mathrm{r}}$ value (measured at $1 \mathrm{kHz}$ ) gradually increased with PANI content up to $14 \mathrm{wt} \%$, and then sharply increased as PANI content increased to $20 \mathrm{wt} \%$. The value of $\varepsilon_{\mathrm{r}}$ jumped from $\sim 210$ (with $14 \mathrm{wt} \%$ PANI) to $5.5 \times 10^{4}$ (with $20 \mathrm{wt} \%$ PANI), and then to an ultra high value of $2.0 \times 10^{5}$ (with $30 \mathrm{wt} \%$ PANI). The values of $\varepsilon_{\mathrm{r}}$ obtained for the PANI-DBSA/PAA polymer composites described in this study were quite remarkable. To the best of our knowledge, these seem to be the highest $\varepsilon_{\mathrm{r}}$ values ever reported for all-polymer composites, including most ceramic dielectrics. In addition, these

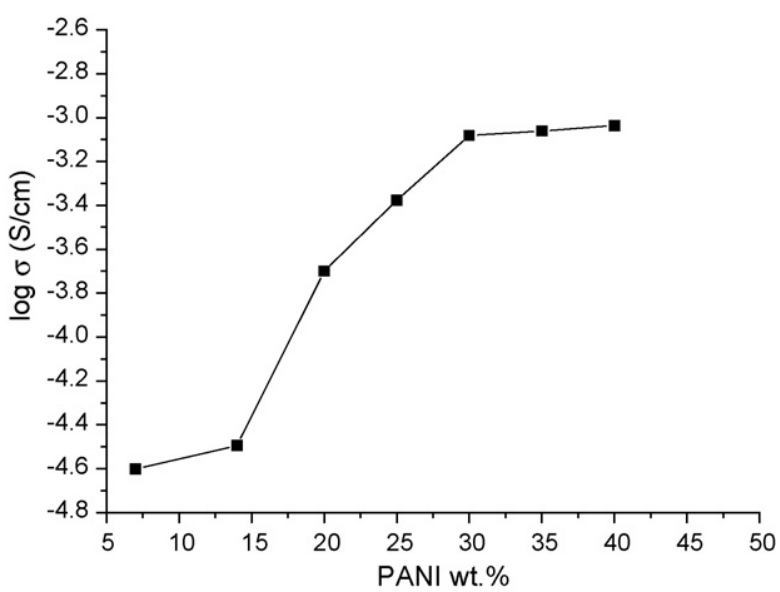

Fig. 6. Dependence of conductivities of PANI-DBSA/PAA composites on PANI content. 


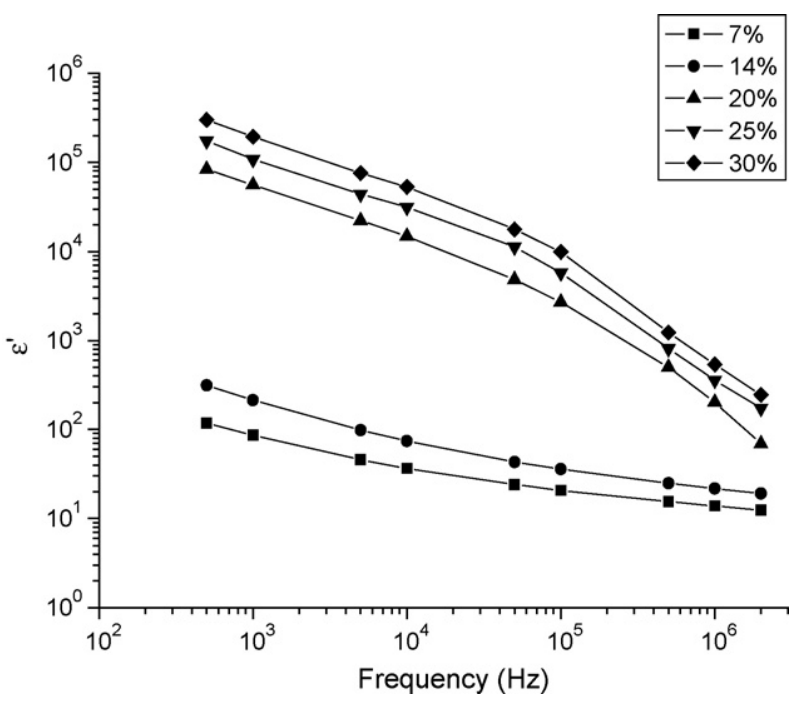

Fig. 7. Dependence of dielectric constants of PANI-DBSA/PAA composites on PANI content and $\mathrm{AC}$ frequency.

results reveal that a threshold in PANI content exists for the dielectric behaviors of these composites. For instance, the dielectric constant, measured over a frequency range of $0.1-100 \mathrm{kHz}$, jumped more than two orders of magnitude as the PANI content was increased from $15 \mathrm{wt} \%$ to $20 \mathrm{wt} \%$. As indicated by the SEM micrograph described above, the majority of nano-size PANI particles were well dispersed in the PAA matrix when the PANI content exceeded $20 \mathrm{wt} \%$. These well-dispersed nano-sized PANI particles served as mini-capacitors within the composites (Figs. 4d and 5). Thus, the high dielectric constant of the PANI-DBSA/PAA composite material can be attributed to the accumulation of these nano-size capacitors. Since these nano-size particles were embedded within the PAA matrix, the charge associated with an individual particle was localized to that particle and could not jump to adjacent particles. In the investigation of a hyper-branched PANI material prepared by a sonication, Goodson and co-worker [23] observed that the PANI microcrystalline domains $(\sim 90 \mathrm{~nm})$ can give rise to large dielectric constants.

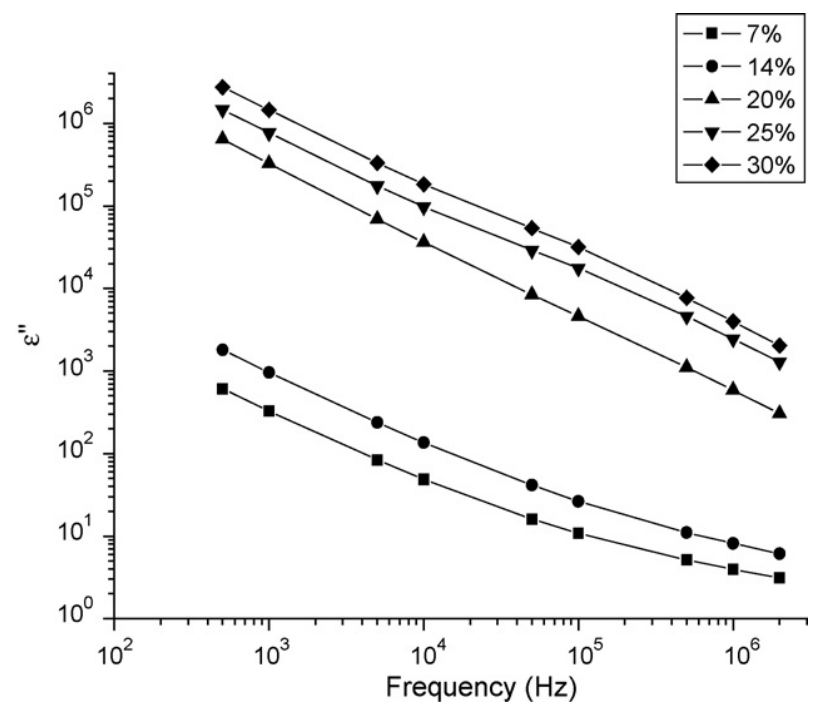

Fig. 8. Dependence of dielectric losses of PANI-DBSA/PAA composites on PANI content and $\mathrm{AC}$ frequency.
Fig. 7 also displays the effect of AC frequency on the dielectric constant values. It reveals the PANI-DBSA/PAA composite gave a $\varepsilon_{\text {r }}$ value of $2.0 \times 10^{5}$ detected at a frequency of $1 \mathrm{kHz}$, and then decreased to $\sim 1 \times 10^{4}$ as the frequency was increased to $100 \mathrm{kHz}$; the $\varepsilon_{\mathrm{r}}$ value declined further to $\sim 800$ and $\sim 250$ when the frequencies were raised to $1 \mathrm{MHz}$ and $2 \mathrm{MHz}$, respectively. Fig. 8 depicts the variation in dielectric loss with PANI content, as well as with frequency. The data revealed that the dielectric loss increased by nearly three orders of magnitude when the PANI content was increased from $14 \mathrm{wt} \%$ to $20 \mathrm{wt} \%$. As shown in the SEM micrographs (Figs. 4 and 5 and Table 1), the distance between the nano-size particles was reduced when the PANI content exceeded $20 \mathrm{wt} \%$. The smaller inter-particle distance facilitated a jumping of the charge from one particle to another, thus, increasing dielectric loss and conductance (Figs. 6 and 8, Eqs. (3) and (5)). In addition, Fig. 8 reveals that dielectric loss decreased linearly with increasing $A C$ frequency. A decrease of ca. 2-3 orders of magnitude was observed when the frequency was increased from $0.1 \mathrm{kHz}$ to $1 \mathrm{MHz}$.

Fig. 7 displays the dielectric constant (i.e., real permittivity) of the composite decreases with increasing frequency. This phenomenon is a relaxation process due to interfacial polarization which is revealed by a maximum of dielectric loss. Unfortunately,
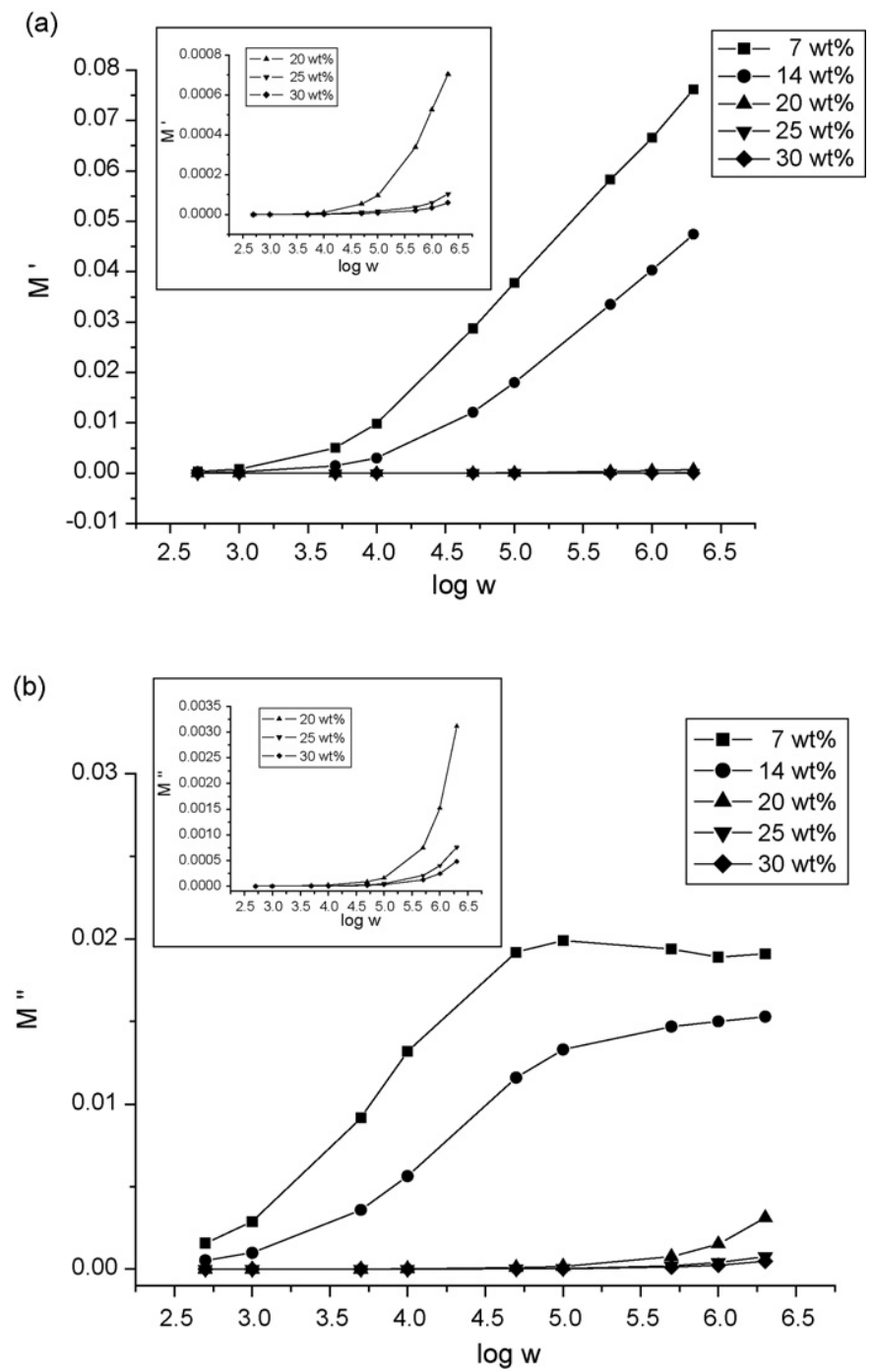

Fig. 9. Electric modulus of (a) real part $\left(M^{\prime}\right)$ and (b) imaginary part $\left(M^{\prime \prime}\right)$ vs. frequency for various PANI-DBSA/PAA composites. 
the dielectric loss maximum peaks are not observed, as shown in Fig. 8 . These peaks are overlapped by dc conductivity contribution. Therefore, a modulus representation of dielectric loss is used to clearly point out the loss peak attributed to the interfacial polarization relaxation process $[38,39]$. The complex electric modulus is derived from the complex permittivity, according to the relationship defined by Macedo et al. [40]. The real and imaginary parts of the electric modulus $\left(M^{\prime}\right.$ and $\left.M^{\prime \prime}\right)$ can be calculated from $\varepsilon^{\prime}$ and $\varepsilon^{\prime \prime}$, as follows [38]:

$M^{\prime}=\frac{\varepsilon^{\prime}}{\left(\varepsilon^{\prime}\right)^{2}+\left(\varepsilon^{\prime \prime}\right)^{2}}, \quad M^{\prime \prime}=\frac{\varepsilon^{\prime \prime}}{\left(\varepsilon^{\prime}\right)^{2}+\left(\varepsilon^{\prime \prime}\right)^{2}}$

Fig. 9 shows the dispersions of $M^{\prime}$ and $M^{\prime \prime}$ of PANI-DBSA/PAA composites, it indicates the presence of the relaxation-time distribution of conduction. $M^{\prime}$ increases greatly after $0.5 \mathrm{kHz}$ and $1.0 \mathrm{kHz}$, respectively, for the composites containing $7 \mathrm{wt} \%$ and $14 \mathrm{wt} \%$ of PANI; whereas $M^{\prime}$ increases after $5 \mathrm{kHz}, 10 \mathrm{kHz}$, and $50 \mathrm{kHz}$ for the composites containing $20 \mathrm{wt} \%, 25 \mathrm{wt} \%$, and $30 \mathrm{wt} \%$ of PANI, which is more evident in the inset of Fig. 9a. In addition, the scale of the increment of $M^{\prime}$ is much larger for the composites containing $7 \mathrm{wt} \%$ and 14 wt\% of PANI (i.e., 0.075 and 0.045 at $5 \mathrm{MHz}$, Fig. 9), as compared to that of the composites containing a higher content of PANI (0.0007, 0.001 and 0.0005 for the composites of $20 \mathrm{wt} \%, 25 \mathrm{wt} \%$, and $30 \mathrm{wt} \%$, respectively, the inset of Fig. 9a). Both results can be rationalized by the distinctly different morphologies displayed by SEM micrographs (Fig. 4a-c vs. Figs. 4d and 5).

Fig. 9b shows the frequency dependence of the imaginary part of the dielectric modulus of these PANI composites. The peak maximum of the $M^{\prime \prime}$ curve seems to exist, but the interval of frequencies used in our measurements was not wide enough to register these maxima. Nevertheless, the $M^{\prime \prime}$ maxima of the composites of $7 \mathrm{wt} \%$ and $14 \mathrm{wt} \%$ of PANI seems to appear at ca. $100 \mathrm{kHz}$ and $5 \mathrm{MHz}$, respectively (Fig. 9b); and, the $M^{\prime \prime}$ maxima are located at the frequencies greater than $5 \mathrm{MHz}$ for the composites containing higher content of PANI (i.e., $20 \mathrm{wt} \%, 25 \mathrm{wt} \%$, and $30 \mathrm{wt} \%$, as shown in the inset in Fig. 9b). Moving the $M^{\prime \prime}$ maximum toward a higher frequency region means an enhancement in dc conductivity of the composite, according to the following expression:

$\sigma=\frac{\varepsilon_{0} \omega}{M^{\prime \prime}} \quad\left(=\varepsilon_{0} \omega \varepsilon^{\prime \prime}\right)$

where $M^{\prime \prime}$ is the reverse of $\varepsilon^{\prime \prime}$, defined as $M^{\prime \prime}=1 / \varepsilon^{\prime \prime}$, and $\omega$ is the relaxation angular frequency [41]. Eqs. (8) and (2) are the same, since $G=\sigma A / d$, and $C o=\varepsilon_{0} A / d$. The enhancement of dc conductivity in the composites with high PANI content is understandable, since more dipolar relaxation occurs in these composites that contain a huge number of nano-scale PANI particles (Figs. 4d and 5).

Fig. 10 presents the complex planes for the electric modulus of the PANI-DBSA/PAA composites. All the curves do not form semicircles, which would correspond to the idealized Debye model with a single relaxation time. As shown in Fig. 10, the composites with low PANI content exhibiting a distorted semicircle pattern, while the composites with high PANI content show a small segment of an arc. The different patterns revealed by these curves also demonstrate the discrepancy in the microstructures between these two categories of composites with different PANI contents. Besides, Matveeva [42] reported that the radius of the arc of the complex plane diagram is dependent on the electrical conductivity of the sample, that is, the larger arc corresponds to lower electrical conductivity. The results presented in Fig. 10 are consistent with the theory mentioned above, i.e., the composite sample with high PANI content that exhibits a small arc in the complex plane diagram would give high electrical conductivity.

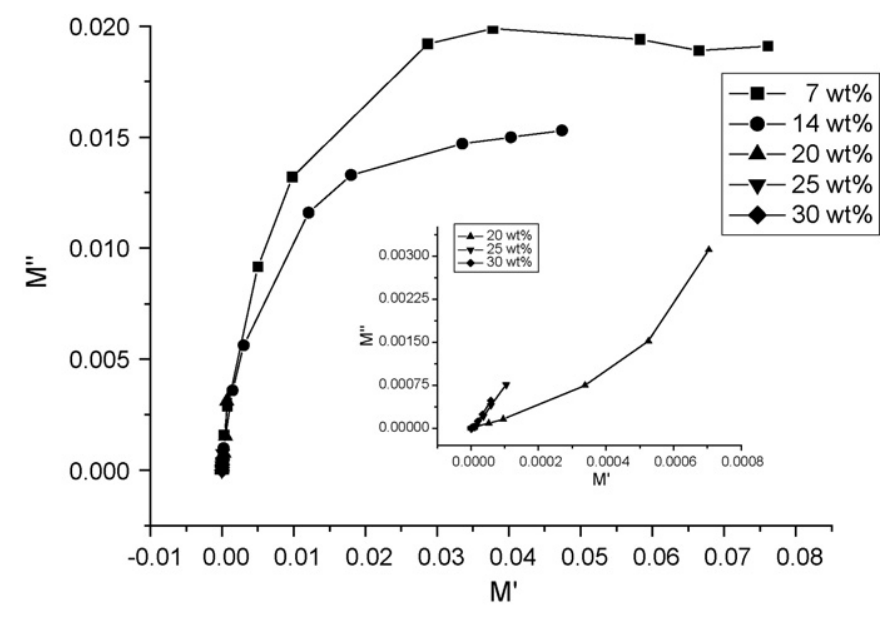

Fig. 10. Complex plane for the electric modulus of various PANI-DBSA/PAA composites.

Fig. 11 displays the variation of the dissipation factor $(\tan \delta)$ with PANI content and with AC frequency. It shows that $\tan \delta$ descends gradually with a frequency for composites with a low PANI content. For composites with $>20$ wt $\%$ of PANI, $\tan \delta$ descends at a low frequency region (i.e., $\geq 40 \mathrm{kHz}$ ) first, then ascends in the high frequency region (curves of $20 \mathrm{wt} \%, 25 \mathrm{wt} \%$ and $30 \mathrm{wt} \% \mathrm{vs} .7 \mathrm{wt} \%$ and $14 \mathrm{wt} \%$, Fig. 11). The increasing $\tan \delta$ curves indicate that as the loss of storage ratio increases, the composite is no longer an insulator and becomes a semi-conductor. This result was also revealed by the sharp increase in conductivity as the PANI content of the composite increased beyond $20 \mathrm{wt} \%$ (Fig. 5 and Table 1 ). Two possible mechanisms can attribute to this sharp increase in conductivity: one is the electric energy associated with the high AC frequency can effectively promote the jumping of electric charge between the nano-size particles; and the other is due to the enhanced dielectric relaxation of the polarization of the PANI particles in a high frequency region [cf. Eq. (8)]. Insulator-metal transitions (IMT) usually are characterized by an abrupt discontinuity in conductivity, the use of the dielectric properties are less favorable, owing to the divergence of the dielectric constant at the percolation threshold point [43]. Based on the results shown in Fig. 11, the dissipation factor

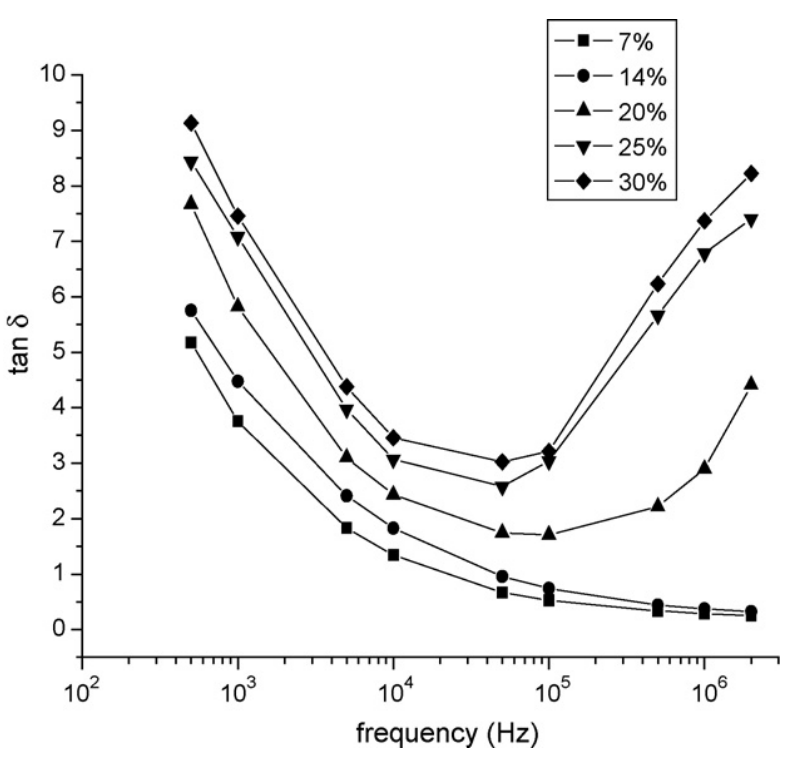

Fig. 11. Variation of dissipation factor with PANI content and with AC frequency. 
$(\tan \delta)$ that represents the ratio of conductance to stored charge for the dielectric material seems to provide a very straightforward indicator for the insulator-metal transition [44-46]. The dissipation factor may be helpful in understanding the mechanism of the transition. Further investigation is needed before this argument can be verified.

\section{Conclusions}

An ultra-high dielectric constant composite of PANI-DBSA/PAA was synthesized using in situ polymerization of aniline in an aqueous dispersion of PAA. The morphology and dielectric/electrical behaviors of the composites were dependent on the ratio of PANI to PAA in the composite. Composites with low PANI content ( $7 \mathrm{wt} \%$ and $14 \mathrm{wt} \%$ ) formed particles (ca. $50-80 \mathrm{~nm}$ ) that were randomly scattered in the PAA matrix-as well as aggregates (ca. $0.2-2.0 \mu \mathrm{m})$. A moderately high dielectric constant in the range of $1100-2600(1 \mathrm{kHz})$ was obtained for composites with low PANI content. Increasing the PANI content to $20 \mathrm{wt} \%$, or higher, elevated the dielectric constant by two to three orders of magnitude. SEM micrographs showed that composites with PANI content in excess of $20 \mathrm{wt} \%$ were comprised of a large number of nanoscale PANI particles (ca. 20-50 nm) that were evenly distributed within the PAA matrix. These PANI nanoparticles acted as numerous mini capacitors within the composite. A $\varepsilon_{\mathrm{r}}$ value of $\sim 2.0 \times 10^{5}$ $(1 \mathrm{kHz})$ was obtained for the composite containing $30 \mathrm{wt} \%$ PANI, which is the highest dielectric constant ever reported for a polymer composite-including most ceramic dielectrics. Results obtained from the electric modulus analyses $\left(M^{\prime}, M^{\prime \prime}\right.$ and $\left.M^{\prime \prime} \mid M^{\prime}\right)$ can account for the morphology difference between the composites of high PANI content and that of low PANI content, as well as the huge increase in electric conductivity exhibited by the composites of high PANI content.

The authors gratefully acknowledge the financial support of the National Science Council of R.O.C. We would also like to thank Prof. Chi-Shun Tu of the Physics Department at FJU for helpful discussion.

\section{References}

[1] J.I. Wojkiewicz, S. Fauveaux, J.L. Miane, Proceedings of the Seventh IEEE International Conference on Solid Dielectrics, Eindhoven, The Netherlands, June 25-29, 2001.

[2] R. Popielarz, C.K. Chiang, R. Nozaki, J. Obrzut, Macromolecules 34 (2000) 5910.

[3] S.K. Bhattacharya, R.R. Tummala, J. Mater. Sci. Mater. Electron. 11 (2000) 253.

[4] S. Koul, R. Chandra, S.K. Dhawan, Polymer 41 (2000) 9305.
[5] P. Chahal, R. Tummala, M.G. Allen, Proceedings of the International Symposium on Microelectron, Orlando, FL, May 28-31, 1996, p. 126.

[6] Y. Rao, C.P. Wong, Polytronic 2002, Proceedings of the Second International Conference on Polymers and Adhesive in Microelectronics and Photonics, Zalaegerszeg, Hungary, June 23-26, 2002.

[7] C.C. Homes, T. Vogt, S.M. Shapiro, S. Wakimoto, A.P. Ramirez, Science 293 (2001) 673.

[8] N. Sugii, H. Yamada, O. Kagaya, M. Yamasaki, K. Sekine, K. Yamashita, M. Watanabe, S. Murakami, Appl. Phys. Lett. 72 (1998) 261.

[9] Y. Rao, S. Ogitani, P. Kohl, C.P. Wong, J. Appl. Polym. Sci. 83 (2002) 1084.

[10] Y. Rao, J. Yue, C.P. Wong, Active Passive Elec. Comp. 25 (2002) 123.

[11] C. Huang, Q.M. Zhang, J. Su, Appl. Phys. Lett. 82 (2003) 3502.

[12] Q.M. Zhang, H.F. Li, M. Poh, F. Xia, Z.Y. Chang, H.S. Xu, C. Huang, Nature 419 (2002) 284

[13] Q.M. Zhang, V. Bharti, X. Zhao, Science 280 (1998) 2101.

[14] I. Vrejoiu, J.D. Pedarnig, D. Bauerle, M. Dinescu, Appl. Phys. Lett. 83 (2003) 2130.

[15] R.R. Grzybowski, F.P. Mccluskey, Int. J. Microelectron. Packaging 1 (1998) 153.

[16] T. Ritter, K.K. Shung, W.S. Hackenberger, H. Wang, T.R. Shrout, Proceedings of the IEEE Ultrasonic Symposium 1 (1999) 1295.

[17] P.K. Singh, A. Chandra, J. Phys. D: Appl. Phys. 36 (2003) L93.

[18] S. Han, X. Liu, J.P. Pan, C. Zhou, Appl. Phys. A 77 (2003) 873.

[19] C. Pecharroman, F. Esteban-Betegon, J.F. Bartolome, S. Lopez-Esteban, J.S. Moya, Adv. Mater. 13 (2001) 1541.

[20] B.G. Kim, S.M. Cho, T.Y. Kim, H.M. Jang, Phys. Rev. Lett. 86 (2001) 3404.

[21] J. Joo, S.M. Long, J.P. Pouget, E.J. Oh, A.G. MacDiarmid, A.J. Epstein, Phys. Rev. B 57 (1998) 9567

[22] P. Dutta, S. Biswas, Subodh Kumar De, Mater. Res. Bull. 37 (2002) 193.

[23] X.Z. Yan, T. Goodson III, J. Phys. Chem. B 110 (2006) 14667.

[24] J. Lu, K.S. Moon, B.K. Kim, C.P. Wong, Polymer 48 (2007) 1510.

[25] B.J. Kim, S.G. Oh, M.G. Han, S.S. Im, Synth. Met. 122 (2001) 297.

[26] J. Stejskal, M. Spirkova, A. Riede, M. Helmstedt, P. Mokreva, J. Prokes, Polymer 40 (1999) 2487

[27] J. Stejskal, P. Kratochvil, Langmuir 12 (1996) 3389.

[28] N. Gospodinova, P. Mokreva, T. Tsanov, L. Terlemezyan, Polymer 38 (1997) 743.

[29] D. Chattopadhyay, S. Banerjee, D. Chakravorty, B.M. Mandal, Langmuir 14 (1998) 1544.

[30] C.P. Chwang, C.D. Liu, S.W. Huang, D.Y. Chao, S.N. Lee, Synth. Met. 142 (2004) 275.

[31] D. Li, Y. Jiang, C. Li, Z. Wu, X. Chen, Y. Li, Polymer 40 (1999) 7065

[32] H. Hu, J.M. Saniger, J.G. Banuelos, Thin Solid Films 347 (1999) 241.

[33] H. Hu, J.L. Cadenas, J.M. Saniger, P.K. Nair, Polym. Int. 45 (1998) 262.

[34] Y. Haba, E. Segal, M. Narkis, G.I. Titelman, A. Siegmann, Synth. Met. 110 (2000) 189.

[35] N. Kuramoto, E.M. Genies, Synth. Met. 68 (1995) 191

[36] D. Walsh, Lectures on the Electrical Properties of Materials, Oxford University Press, 1984 (Chapter 10).

[37] I. Bunget, M. Popescu, Physics of Solid Dielectrics, Elsevier, NY, 1978 (Chapter 6).

[38] M.K. Ram, S. Annapoorni, S.S. Pandey, B.D. Malhotra, Polymer 39 (1998) 3399.

[39] H.T. Lee, C.S. Liao, S.A. Chen, Makromol. Chem. 194 (1993) 2443.

[40] P.B. Macedo, C.T. Moynihan, R. Bose, Phys. Chem. Glasses 13 (1972) 171

[41] M.G. Han, S.S. Im, J. Appl. Polym. Sci. 82 (2001) 2760.

[42] E.S. Matveeva, Synth. Met. 79 (1996) 127.

[43] C. Pecharroman, J.S. Moya, Adv. Mater. 12 (2000) 294.

[44] J. Joo, E.J. Oh, G. Min, A.G. MacDiarmid, A.J. Epstein, Synth. Met. 69 (1995) 251.

[45] O. Levy, D. Stround, J. Phys.: Condens. Matter. 9 (1997) L599.

[46] V.N. Prigodin, A.J. Epstein, Synth. Met. 125 (2002) 43. 